\title{
Extended expression of MaKN1 contributes to the leaf morphology in aquatic forms of Myriophyllum aquaticum
}

\begin{tabular}{|r|l|}
\hline Journal: & Botany \\
\hline Manuscript ID: & cjb-2015-0077.R1 \\
\hline Manuscript Type: & Note \\
\hline Date Submitted by the Author: & 08-Jun-2015 \\
\hline Complete List of Authors: & $\begin{array}{l}\text { Shafiullah, MD; University of Prince Edward Island, Biology } \\
\text { Lacroix, Christian; University of Prince Edward Island, Biology }\end{array}$ \\
\hline Keyword: & $\begin{array}{l}\text { Myriophyllum, aquatic growth form, MaKN1, prolonged expression, } \\
\text { alteration in leaf morphology }\end{array}$ \\
\hline \multicolumn{2}{|l}{} \\
\hline
\end{tabular}




\title{
Article type: NOTE
}

Extended expression of MaKN1 contributes to the leaf morphology in aquatic forms of Myriophyllum aquaticum.

\section{Md. Shafiullah and Christian R. Lacroix*}

\author{
Department of Biology, University of Prince Edward Island, 550 University avenue, \\ Charlottetown, PE C1A 4P3, Canada
}

*For correspondence. E-mail lacroix@upei.ca 


\begin{abstract}
Myriophyllum aquaticum is heterophyllous in nature with highly dissected simple leaves consisting of several lobes. KNOX1 (KNOTTED1-LIKE HOMEOBOX) genes are believed to have played an important role in the evolution of leaf diversity. Up-regulation of KNOX1 during leaf primordium initiation can lead to leaf dissection in plants with simple leaves, and, if overexpressed can produce ectopic meristems on leaves. A previous study on KNOX1 gene expression in the aerial form of this species showed that this gene is expressed in the shoot apical meristem (SAM), as well as in leaf primordia P0 to P8. Based on these results, it was hypothesized that the prolonged expression of the MaKN1 (Myriophyllum aquaticum Knotted1-like homeobox) gene beyond P8, might play an important role in the generation of more lobes, longer lobes, and hydathode formation in the aquatic leaves of M. aquaticum. The technique of in situ hybridization was carried out using a previously sequenced $300 \mathrm{bp}$ long fragment of MaKN1 to determine the expression patterns of this gene in the shoot of aquatic forms of the plant. Expression patterns of MaKN1 revealed that the SAM and leaf primordia of aquatic forms of M. aquaticum at levels P0 (youngest) to P4 were distributed throughout these structures. The level of expression of this MaKN1 gene progressively became more localized to lobes in older leaf primordia (levels P5 to P12). Previous studies of aerial forms of this plant showed MaKN1 expression until P8. Our results with aquatic forms show that the highly dissected leaf morphology in aquatic forms was the result of the prolonged expression of MaKN1 beyond P8. This resulted in the formation of elongated and slightly more numerous lobes, and hydathodes in aquatic forms. These findings support the view that KNOX1 genes are important developmental regulators of leaf morphogenesis and have played an important role in the evolution of leaf forms in the plant kingdom.
\end{abstract}


Key Words: Myriophyllum, aquatic growth form, MaKN1, prolonged expression, alteration in leaf morphology. 


\section{Introduction}

The shoot apical meristem (SAM) consists of self-renewing cells that produce most of the lateral organs in plants (Barton 2001; Gallois J-L et al. 2002; Byrne 2005). A mass of undifferentiated cells ultimately generates determinate organs like leaves in the peripheral region of the SAM (Steingraeber and Fisher 1986; Barton 2001; Kessler and Sinha 2004) while those in the central region of the shoot maintain their indeterminacy (Byrne 2005). A series of coordinated processes specified by genes are involved in shaping leaves (Kessler and Sinha 2004; Byrne 2005). The application of molecular techniques to locate the activity of specific genes can further help our understanding of the roles of these genes in leaf development and evolution (Rothwell et al. 2014).

KN1 (Knotted1-like homeobox) genes, members of the homeobox gene family, play an important role in plant development. They are down-regulated during the development of simple leaves (Smith et al. 1992; Bharathan et al. 2002) with some exceptions as in sunflower (Tioni et al. 2003). However, they are up-regulated during the formation of leaf primordia in ferns (Bharathan et al. 2002; Sano et al. 2005) or in some plants with compound leaves such as tomato (Chen et al. 1997). KN1 genes are classified into two groups (class 1 and class 2) on the basis of their sequence similarity in their homeodomain and expression patterns (Kerstetter et al. 1994).

The roles of $K N 1$-like homeobox genes in plant development were studied in different model species with simple (Chuck et al. 1996; Tioni et al. 2003; Muller et al. 2006; Barth et al. 2009) and compound leaves (Hareven et al. 1996; Chen et al. 1997; Janssen et al. 1998; Sano et al. 2005). Although their roles are diverse in development, they are instrumental in the maintenance of meristematic tissue for organ development in vegetative and reproductive parts of plants. 
Knotted1-like gene expression in compound and simple leaf development

The tomato plant has compound leaves with unipinnate leaf morphology. Wild type leaves consist of a rachis, a terminal leaflet, and three to four pairs of dentate and petiolated leaflets. Sometimes, folioles (additional smaller leaflets) appear between the leaflets on both sides of the rachis or on the petiolules of leaflets. Misexpression of maize KN1 in transgenic tomato drastically increases leaf complexity. In this case, leaves are subdivided up to six times and produce supercompound leaves (Hareven et al. 1996). LeT6, a class 1 KNOX gene is related to the production of compound leaves in tomato. The SAM and axillary buds express this gene throughout. Its expression is also evident in developing leaf primordia, the adaxial region of older primordia, leaflet primordia, and developing leaflet margins in wild type plants.

Overexpression of LeT6 in transgenic tomato results in an increase in compounding in leaf morphology (Chen et al. 1997).

Another extensive study (Janssen et al. 1998) on overexpression of LeT6 in transgenic tomato showed enhanced tissue indeterminacy and increased leaf complexity. In this case, most of the transformed tomato plants produced leaves with ectopic meristems that led to the formation of extra organs. Ectopic meristems on the margins and in the axils of the leaflets produced determinate structures such as new leaf primordia. In situ hybridization of LeT6 in wild type tomato showed high levels of expression in older leaf primordia during the initiation of leaflet primordia, in vascular tissues in the leaf, and in the adjoining axial vasculature. In addition, vascular tissues in the marginal blastozone (a term proposed by Hagemann and Gleissberg in 1996 to denote the marginal meristems of leaves capable of organogenesis) of the leaf and at the junction between the rachis and petiolule, overexpressed LeT6 in transgenic tomato compared to the wild type. 
The role of KNOX genes was also studied in simple leaves such as the serrated leaves of Kohleria. Recombinant Kohleria transformed with KNAP1 (apple KNOX) resulted in the overexpression of this gene and it severely altered leaf form from simple to highly dissected (Barth et al. 2009). The overexpression of another KN1 gene (KNAT1) of Arabidopsis generated lobes with stipules in the position of serrations. Floral and vegetative ectopic meristems also developed on the adaxial surface of the leaves in the sinus region close to the veins (Chuck et al. 1996). The role of KN1 was also studied in deeply-lobed leaves of dandelion. The deeplylobed leaves of dandelion are the result of endogenous DandeKnox1 (Dandelion Knox1) expression. Transgenic dandelion transformed with bkn1 and bkn2 (barley Knox1 and 2 overexpression) altered leaf form from simple to compound. As a result, the number of leaflets increased in successive leaves. In addition, meristematic outgrowths appeared in the sinuses of the lobes or leaflets and on the left and right at the base of the leaflets as hairy white bulges (Muller et al. 2006).

These studies on genetic transformation of $K N 1$ genes into model species with simple or compound leaves show that the over-expression of this gene lengthens tissue indeterminacy. As a result, leaf complexity increases, compound leaves become more compound, and dissected leaves appear in simple-leaved plants. Sometimes, ectopic meristems are formed on the leaves, and lead to the production of new structures such as secondary lobes, inflorescences or floral organs on the leaves.

\section{Expression patterns of MaKN1 in the aerial form of Myriophyllum aquaticum}

Bourque and Lacroix (2011) used non-model plant species Myriophyllum aquaticum to investigate the role of Knotted1-like genes in leaf development of this highly dissected simple leaf plant. They showed KN1-like gene activity in aerial forms of this plant. The expression of MaKN1 was documented in incipient leaf primordia (P0). This is unlike expression patterns in 
most of the plant species reported thus far with the exception of $K N 1$ expression in ferns (Bharathan et al. 2002; Sano et al. 2005) or LeT6 in tomato (Chen et al. 1997). MaKN1 expression was also detected throughout leaf primordia at positions P1-3. Additionally, expression of MaKN1 was evident in the vasculature of the developing stem, provascular strands, subtending leaf primordia, and leaf traces. The expression of this gene persisted until P8. The authors also hypothesized that if MaKN1 expression is prolonged, the lobes themselves might develop lateral elements or might increase in complexity because small appendages were visible on leaves during early stages of development (Shafiullah and Lacroix 2013). These appendages have been characterized as multicellular hairs (Perrot 1900), enations, scales, hydathodes, glands, or even 'pseudo-stipules' (Orchard 1979). For the purposes of this article, we adopted the use of the reportedly popular term hydathode as specified in Orchard (1979), which does not imply that the structure has an excretory function.

The study of early stages of leaf development in aerial and aquatic forms of M. aquaticum showed that the number of lobes is slightly greater in aquatic leaves and that there are hydathodes in the axil of lobes, on the lobes and at the tips of the lobes in aquatic leaf forms. Hydathodes start to develop in the axil of lobes and on the lobes at stage P7 (Shafiullah and Lacroix, 2013). Based on the results of this previous study, it was hypothesized that the prolonged expression of MaKN1, beyond P8, might play an important role in the generation of more lobes, longer lobes and hydathode formation in the aquatic leaves of M. aquaticum.

\section{Materials and Methods}

Total RNA extraction and cDNA synthesis

Myriophyllum aquaticum was grown in potting soil and in aquaria to generate the aerial and aquatic forms respectively, in a greenhouse (natural lighting, daytime temperature: $20-25^{\circ} \mathrm{C}$ and 
humidity: $40 \%$, nighttime temperature: $16-19^{\circ} \mathrm{C}$ and humidity: $\left.40 \%\right)$. The RNeasy Plant Mini Kit was used to extract total RNA from the crushed fresh plant materials (QIAGEN Inc., Ontario, Canada). qScript cDNA Supermix (Quanta Biosciences Inc., Ontario, Canada) was used to produce cDNA (complementary DNA) using RNA as template. Synthesized cDNA was used as the template for the PCR amplification of MaKN1 gene using GoTaq Hot Start Green Master Mix, 2X Kit (Promega, Madison, USA) and the same primers generated in Bourque and Lacroix (2011).

Amplified gene cloning and sequencing

The TOPO TA Cloning Kit Dual Promoter (Invitrogen, Ontario, Canada) was used for gene cloning. EZ-10 Spin Column Plasmid DNA MiniPreps Kit (Bio Basic In., Ontario, Canada) was then used to extract cloned DNA. Plasmid DNA extracted from 9 white colonies and 1 blue (negative control) colony were tested by PCR amplification of the gene fragment that was inserted into the vector. The plasmid DNA of 9 white and 1 blue colony (negative control) were sent to Genome Québec (Québec, Canada) for sequencing, in order to determine the orientation of the inserts and for further confirmation of the inserts of interest. Sequences blasted on Genbank showed that 4 out of 9 recombinant plasmid DNA samples contained a sequence similar to the sense strand of MaKN1 (Bourque and Lacroix 2011) which was used to produce sense probes (negative control) for in situ hybridization. The remaining 5 of 9 were similar to the anti-sense strand of MaKN1 and were used to produce anti-sense probes.

\section{Probe synthesis}

All recombinant plasmids were linearized by restriction enzyme digestion (Invitrogen, Ontario, Canada) to synthesize sense and anti-sense RNA probes. The total reaction volume was mixed gently and incubated at $37^{\circ} \mathrm{C}$ in a water bath for $1 \mathrm{hr}$. The reaction volume was then incubated 
for 20 minutes at $65^{\circ} \mathrm{C}$ on a heating block in order to inactivate the enzyme. Sense (negative control) and anti-sense probes were synthesized using Dig-RNA Labeling Kit (Roche, Laval, Québec, Canada).

\section{Paraffin embedding and sectioning of shoot tips}

The shoot tips of aquatic plants were excised and preserved in ice cold fixative $[4 \%(\mathrm{w} / \mathrm{v})$ paraformaldehyde, 4\% (v/v) dimethylsulfoxide in $1 \mathrm{X}$ phosphate buffer saline (PBS)]. The shoots were dissected and then vacuum infiltrated to allow sufficient penetration of the fixative in tissues. The fixative was replaced with fresh fixative and tissues were kept at $4^{0} \mathrm{C}$ overnight. On the eighth day, vacuum infiltrated shoot tips were removed from the fixative and embedded in paraffin. The paraffin-embedded tissues were sectioned using a manual rotary microtome (American Optical Company, Spencer, 820 Microtome). Seven $\mu \mathrm{m}$ thick longitudinal and cross sections were mounted on Probe On Plus slides (Fisher Scientific) which were pre-warmed with $2 \mathrm{ml}$ diethylpyrocarbonate (DEPC)-treated water on a slide warmer set at $42^{\circ} \mathrm{C}$. Sections were then placed on a layer of DEPC-water onto slides to achieve flattening of the tissues. Excess water was drained and slides were kept on the slide warmer overnight for adequate adherence of the tissues to slides.

\section{In situ hybridization}

In situ Hybridization was performed using IsHyb In Situ Hybridization Kit (Biochain Institute Inc., Burlington, Ontario, Canada) according to the protocol that was provided but with some slight modifications. Tissue slides were soaked in Citrisolv for 15 minutes twice. Slides were then rehydrated from $100 \%$ ethanol to distilled water at 5 mins/step as follows: $100 \%$ I, $100 \%$ II, $95 \%$, $90 \%, 80 \%, 60 \%, 30 \%$ and distilled water. Rehydrated tissues were fixed with $4 \%$ paraformaldehyde in DEPC-PBS for 20 minutes at room temperature. Tissues were then 
washed with DEPC-PBS twice at room temperature for 5 minutes. Proteinase $\mathrm{K}$ was added to $150 \mathrm{ml}$ proteinase $\mathrm{K}$ buffer in a concentration of $1 \mu \mathrm{g} / 1.5 \mathrm{ml}$. Tissues were incubated in proteinase $\mathrm{K}$ for 30 minutes at $37^{\circ} \mathrm{C}$. Proteinase $\mathrm{K}$ treated tissues were washed with DEPC-PBS for 5 minutes at room temperature. Paraformaldehyde (4\% solution) was used to fix the tissues for 15 minutes and fixed tissues were then rinsed with DEPC-water once. One hundred microliters of pre-hybridization solution was spread on the surface of the tissue section and incubated in a box containing a water-soaked towel for 4 hours at $50^{\circ} \mathrm{C}$ in an incubator. Three hundred nanograms of sense (negative control) and anti-sense probe were added separately to $100 \mu \mathrm{l}$ of ready-to-use hybridization solution. A mixture of hybridization and probe solution was spread on the surface of the tissue sections. Tissues were incubated in a box containing a water-soaked towel at $45^{\circ} \mathrm{C}$ for 16 hours.

Hybridized tissues were washed with 2X and 1.5X SSC (Sodium Chloride and Sodium Citrate) solution for 10 minutes each at $45^{\circ} \mathrm{C}$ in an incubator. A solution of $0.2 \mathrm{XSC}$ was then used to wash the tissues twice for 20 minutes at $37^{\circ} \mathrm{C}$. Tissues were then incubated in $1 \mathrm{X}$ blocking solution for 2 hours at room temperature to reduce the background signal from the tissue sections.

AP (Alkaline Phosphatase)-conjugated anti-digoxigenin antibody was diluted with 1X PBS at the ratio of 1:1000 [IsHyb In Situ Hybridization (ISH) Kit, Biochain Institute Inc., Burlington, Ontario, Canada]. A diluted antibody solution was spread on the tissue sections which were incubated for 4 hours at room temperature. Tissue sections were then washed 3 times with $1 \mathrm{X}$ PBS for 10 minutes at room temperature. Alkaline phosphatase buffer (1x) was then used to wash the tissues twice at room temperature for 5 minutes. A $6.6 \mu$ l solution of NBT (nitro-blue tetrazolium chloride) and $3.3 \mu \mathrm{l}$ solution of BCIP (5-bromo-4-chloro-3-indolyphosphate p-toluidine salt) were mixed with $1 \mathrm{X}$ alkaline phosphatase buffer and the mixture was then spread onto each tissue 
section. Sections were incubated in the dark for 2 hours at room temperature. The NBT/BCIP solution was decanted when colour was visible on the tissues. Slides were then rinsed with distilled water and air-dried. Permount (Fisher Scientific) was used to mount coverslips over the tissues. Slides were viewed for MaKN1 gene expression using a compound light microscope (Olympus, BH-2) and images recorded using Leica DC480 camera.

\section{Results}

Isolation of MaKN1 gene fragment

A pair of primers previously designed by Bourque and Lacroix (2011) was used to amplify, clone, and sequence a 310 bp MaKN1 gene fragment. The sequence was 'blasted' to confirm its identity using NCBI (National Centre for Biotechnology Information) nucleotide databases. It showed a $100 \%$ match with a previously submitted sequence by the Lacroix lab in Genbank, MaKN1_EU203679 used in the aerial leaf study (Bourque and Lacroix 2011).

Visual analysis of shoot apices of aquatic and aerial M. aquaticum

M. aquaticum produces highly dissected simple leaves in aerial and aquatic forms, however, their phenotypes differ strikingly. The lobes of aquatic leaves are more elongated than their aerial counterparts (Fig. 1A \& B). Hydathodes are visible in the axils of lobes, on the lobes themselves, and at the tips of the lobes (Fig. $1 C \& D ; A A, A L \& A T$ ) only in aquatic leaf forms. These non-vascularized outgrowths were also evident in nodes of aquatic and aerial stems (Fig. $1 E \& F, A N)$. However, the number of these structures (AN) varies in both growth forms, and the nodes of aquatic forms contain more of them (Fig. 1, AN).

Localization of MaKN1 transcripts in aquatic M. aquaticum using in situ hybridization 
In situ hybridization using digoxigenin-labelled RNA anti-sense probes was carried out in order to determine the location of our MaKN1 transcripts and expression patterns in aquatic shoot tips of $M$. aquaticum. Strong hybridization signals were detected in longitudinal and cross sections of shoot apices (Fig. 2A-C \& Fig. 3A-C, respectively). This signal shows up as a reddish stain. There was no signal in the negative control hybridization of digoxigenin-labelled RNA sense probes to tissues (Figs. 2D, 3D).

\section{MaKN1 expression in longitudinal sections}

As shown in the longitudinal sections (Fig. 2A), the expression of MaKN1 is visible in the SAM (M) and meristem of the axillary bud (MA). In both cases, the expression pattern infers that a high number of MaKN1 transcripts were present evenly throughout the meristems. The location of incipient leaf primordia was not detectable in the SAM (Fig. 2A). This location would be detectable if the down-regulation of MaKN1 was in fact taking place in the SAM (M) or in the apical meristem of the axillary buds (MA). P1 to P5 leaf primordia evenly expressed MaKN1 throughout (Fig. 2A). P5 of the axillary bud exhibited expression predominantly in the adaxial region (Fig. $2 \mathrm{~A},{ }^{*}$ ) of the primordium. The level of expression (intensity of staining) decreased in successively older leaves and older portions of the primordia (P6-12). For example, part of P6 nearest to the stem showed more expression than the tip or older lobes (Fig. 2A). This phenomenon was observed in the older primordia as well. Expression was also visible in the marginal zone, and in the lobes located in the proximal part of P7 (Fig 2A, LP). A reduction in expression was visible in the distal part of P7. In P8, MaKN1 expression was obvious in the centre of the midrib and in lobes near the proximal region (Fig. 2A). On the other hand, the outer portion of the midrib exhibited less MaKN1 expression. Expression pattern of MaKN1 in P9 was similar to the previous leaf positions P7 and P8. However, the distal part of P9 primordia showed less signal than in the P7. A faint expression was visible in the centre of the midrib (CR), 
and lobes of P10 leaves. A similar expression was also observed in P11. On the other hand, it was absent from the outer portion of the midrib (OR) of P12 (Fig. 2A).

MaKN1 expression patterns were also observed in the sub-apical region (SA) of the shoot apex where the initiation of vascular tissues and pith takes place (Fig. 2B). Expression was obvious in the differentiating vascular strands (VS) of the stem, in the center of the midrib (CR) and subtending leaf vasculature (LV) connecting to the vascular strand (VS) of the stem. No expression was observed in the differentiated pith (PH) (Fig. 2B).

Lobes in the proximal part (LP) of the leaves exhibited a strong hybridization signal in all cases beyond P5 (Fig. 2C). In comparison, a lower level of expression was apparent in the lobes located in the distal part of the leaves beyond P5. This pattern became more accentuated at higher (older) leaf positions. Expression was also observed in the subtending leaf vasculature (LV) connecting to the lobes. No signal was observed in the outer portion of the midrib (OR) at stage P8 (Fig. 2C).

\section{MaKN1 expression in cross sections}

The cross sections of the shoot apex of aquatic forms of $M$. aquaticum also provided a detailed snapshot of the hybridization signal of MaKN1 across a series of leaves at different stages of development. Serial sections from the top part of the shoot apex to the older lower levels of the shoot tip showed variations in MaKN1 expression (Fig. 3A-C). For example, variations in hybridization signal were obvious between internodal (Fig. 3A, B) and nodal (Fig. 3C) regions. MaKN1 expression was also visible in the vascular cylinder (VC) and outer portion of the internode (OI) (Fig. 3A). Expression also extended to the central region of the stem where the pith will be located. However, a gradual reduction in the expression pattern was observed in more differentiated pith tissues in successive sections (Fig. 3B, C). The adaxial region (Fig. 3A, 
$\mathrm{P}^{\star}{ }^{\star}$ ) of the leaf, as the lobes were forming, also exhibited a strong expression pattern of MaKN1. The signal gradually decreased in the midrib region $(C R)$ in successively older leaves (Fig. 3A, P5-9). A similar expression pattern was also observed in figure 3B that represents a lower internodal region. This region showed reduced expression in most of the area of the pith, and a strong signal in the vascular cylinder and outer portion of the internode. Expression was conspicuous in the lobes (L) (Fig. 3B, P6) and its site of attachment to the leaf (SL) (Fig. 3B, P6). As in the longitudinal sections, expression patterns become progressively weaker in older leaves. By P9, the MaKN1 signal was not visible in midrib areas as well as in the older lobes (OL) (Fig. 3A, B).

Differences in expression patterns of MaKN1 were observed between the nodal (Fig. 3C, P7) and internodal portions (Fig. 3A, B) of the stem. The expression was confined to the vascular cylinder (VC), and in the vascular tissues supplying the leaves (VL) (Fig. 3C). Expression was absent in the pith around the vascular cylinder (VC) and vascular tissues connecting the leaves $(\mathrm{VL})$ and at the bases of the leaves (BL) (Fig. 3C). MaKN1 expression was observed at the base of the leaves where hydathodes (AN) were initiated (Fig. $3 \mathrm{C}$ ). The lobes in the proximal region (LP) close to the node showed MaKN1 gene expression evenly throughout. This level of expression in lobes decreased at increasingly older leaf positions and became more restricted to the proximal portion of the leaf.

\section{Discussion}

KN1 genes with variable expression patterns and functions have been isolated from different plant species (Vollbrecht et al. 1991; Ma et al. 1994; Kerstetter et al. 1994; Lincoln et al. 1994; Serikawa et al. 1996; Watillon et al. 1997; Serikawa et al. 1997; Sundas-Larsson et al. 1998; Sentoku et al. 1998; Serikawa and Mandoli 1999; Hofer et al. 2001; Rosin et al. 2003; Tioni et al. 2003; Sano et al. 2005; Harrison et al. 2005; Groover et al. 2006; Huang et al. 2009; Bourque 
and Lacroix 2011). These genes function in a variety of structures such as shoot apical meristems (SAM), axillary buds, young leaf primordia, floral primordia, differentiating vascular tissues of the stems, vascular tissues of the leaves, cells adjacent to vascular tissues, nodal and internodal tissues, provascular cylinder, and developing pith.

The MaKN1 anti-sense probes used for in situ revealed that it is expressed at different stages of development in determinate organs such as leaves and indeterminate structures such as the SAM and the developing stem of aquatic forms of $M$. aquaticum. A similar result was also reported by Bourque and Lacroix (2011) in aerial forms of this plant. There are several kinds of class 1 and $2 K N 1$ genes that also have similar expression patterns in indeterminate and determinate organs. For example, Kerstetter et al. (1994) reported seven types of class 1 KN1 genes that are expressed in vegetative meristems and floral primordia in maize. JnKNAT3 is a class 2 gene isolated from Juglans nigra L. and it is expressed in immature and mature leaves, pith meristem, vascular cambium, roots and flowers (Huang et al. 2009). Therefore, it is likely that our designed probes that include a conserved block of the homeodomain of MaKN1, bind to other class 1 or class $2 \mathrm{KN} 1$ genes if they are expressed in different parts of the aquatic forms of $M$. aquaticum. This conclusion was also reached by Bourque and Lacroix (2011) for aerial forms of this plant. Even though the main goal of this study was to use a comparative approach by probing with the same MaKN1 fragment, our hope is to pursue this work by presenting a full clone of MaKN1 that will allow us to assign the gene to one of the class $1 \mathrm{KNOX}$ gene clades found in eudicots.

The expression of MaKN1 gene was observed in the SAM (shoot apical meristem), MA (apical meristem of axillary buds), and in the sub-apical region (SA) where ground meristems are located. KN1 genes are mainly expressed in meristematic cells (Tioni et al. 2003; Hay et al. 
2004) and their expression is needed to keep the SAM functional (Gallois et al. 2002; Hay et al. 2003; Sano et al. 2005; Ito et al. 2008) and for producing lateral organs (Hay et al. 2002). In general, KN1 genes are not expressed in the incipient leaf primordia in seed plants (Bharathan et al. 2002). Exceptions to this finding are documented in aquatic and aerial (Bourque and Lacroix 2011) forms of M. aquaticum, in seedless vascular plants like the fern Ceratopteris richardii (Sano et al. 2005), in Anogramma chaeophylla (Bharathan et al. 2002), and in tomato (Chen et al. 1997). MaKN1 expression in apical meristems and leaf primordia in aquatic forms of $M$. aquaticum resembled the expression patterns of $K N 1$ in aerial forms of $M$. aquaticum (Bourque and Lacroix 2011), and even those of tomato (Chen et al. 1997), the fern Ceratopteris richardii (Sano et al. 2005), and Anogramma chaeophylla (Bharathan et al. 2002).

The peripheral region of the stem and developing vascular strands (VS) also express KN1 gene in the aquatic forms of $M$. aquaticum. Expression is not visible in the pith and a gradual reduction of expression was also reported in later stages of development. Similar findings were also reported by Bourque and Lacroix (2011) in aerial forms of M. aquaticum and Smith et al. (1992) in maize. Expression patterns in aquatic forms of $M$. aquaticum show that MaKN1 is expressed throughout the SAM and leaves in P1-4 whereas Bourque and Lacroix (2011) observed this phenomenon in aerial forms in P1-3 only. A reduction in expression of MaKN1 to more localized portions of the leaf primordia was observed to occur at stage P5 in aquatic forms. This gradual reduction in expression continued until P12. In comparison, this reduction of MaKN1 expression was first observed in P4 and then continued to decline until P8 in aerial forms of M. aquaticum. Expression was also detected in the lower leaf lobes of P8 and at the base of P8 leaves. There was no expression detected in P9 in aerial forms of $M$. aquaticum (Bourque and Lacroix 2011). Lobes in the proximal part of the leaves retain their expression 
during initiation in both forms. As new lobes are initiated, the expression is no longer visible in the older lobes located in the distal part of the leaves. MaKN1 expression patterns in $M$. aquaticum persisted for a longer period of time in aquatic forms (until P12) in comparison to its aerial counterpart (until P8).

The major role of class $1 \mathrm{KN} 1$ genes is to maintain tissue indeterminacy, keeping cells in an undifferentiated meristematic state. Hay et al. (2003) showed the activity of KN1 in P2-7 in a steroid-inducible system. This system can control the level and timing of $K N 1$ expression in a dose dependent manner. Their findings confirmed that the extent of lobing in leaves is proportional to the level of expression of $K N 1$, that is, lobe formation continues as long as $K N 1$ is expressed. Findings from our study showed that MaKN1 was expressed until P12 in aquatic forms, in comparison to P8 in aerial forms (Bourque and Lacroix 2011). Consequently, it was assumed there would be changes in plant morphology as a result of prolonged expression (beyond P8) of MaKN1 in aquatic forms. The expression patterns of MaKN1 in aquatic forms of M. aquaticum combined with previous results of expression patterns in aerial forms (Bourque and Lacroix 2011) support the idea that a prolonged expression of MaKN1 contributes to the development of different leaf morphologies in aquatic forms of this plant. Therefore, findings reported in this study support: 1) the prolonged expression (beyond P8) of MaKN1 in aquatic forms of $M$. aquaticum linked to a longer period of tissue indeterminacy as well as more numerous lobes in mature leaves, and 2) the development of hydathodes in the axils of lobes, on the lobes, at tips of the lobes, and in nodal regions. The hydathodes produced on the lobes of aquatic leaf forms of $M$. aquaticum could represent secondary lobes due to the prolonged expression of MaKN1, in a manner similar to what was documented with KNAT1 overexpression in A. thaliana (Chuck et al. 1997). It is important to note that hydathode formation happens naturally in the context of aquatic forms of M. aquaticum. 
Prolonged expression (beyond P8) of MaKN1 supports the idea that KN1 plays an important role in determining cell fate (Smith et al. 1992; Hay and Tsiantis 2006). On that basis, it is suggested that strong expression in the proximal part of the leaves and its prolonged existence (beyond P8) might lead to a slight increase in the number of lobes (Shafiullah and Lacroix 2013) and also more elongated lobes in aquatic forms of $M$. aquaticum. Barth et al. (2009) transformed simple-leaved Kohleria with KNOX gene. They showed that the overexpression of this gene extends the indeterminacy of the tissues in simple leaves of that plant. As a result, simple leaves are replaced by lobed leaves. Lobing is more pronounced in the proximal part of leaves and the length of these lobes is also greater than the actual length of the leaves. However, the authors did not document the finding that lobes in the proximal part are visually longer than the lobes located in the distal part of the leaves even though it is evident on the figures of the transgenic leaves that were produced. Interestingly, these types of variations in morphology occur naturally in M. aquaticum. Therefore, this plant is a good working model to observe variations in leaf morphology without resorting to transformation. Observations of lobe development in $M$. aquaticum showed that the lobes in the proximal part of the aquatic leaves of M. aquaticum are longer than the lobes in the distal part. This extended tissue indeterminacy in this region of leaves as noted in our extended expression patterns supports the potential for morphological changes such as longer lobes and greater number of lobes in aquatic leaf forms of $M$. aquaticum.

Based on the expression patterns observed in leaves and shoots of $M$. aquaticum, it is suggested that there are different active KNOX genes in this plant. Consequently, it is likely that different KNOX genes are expressed in different parts of the plant, hence our interest in producing a full clone of MaKN1, and possibly other KN1 genes in M. aquaticum in future studies. 


\section{ACKNOWLEDGEMENTS}

This investigation was supported by a grant from the Natural Sciences and Engineering Research Council of Canada to CRL. 


\section{LITERATURE CITED}

Barth S, Geier T, Eimert K, Watillon B, Sangwan RS, Gleissberg S. 2009. KNOX overexpression in transgenic Kohleria (Gesneriaceae) prolongs the activity of proximal leaf blastozones and drastically alters segment fate. Planta 230: 1081-1091.

Barton MK. 2001. Leaving the meristem behind: regulation of KNOX genes. Genome Biology 2(1): 1002.1-1002.3.

Bharathan G, Goliber ET, Moore C, Kessler S, Pham T, Sinha NR. 2002. Homologies in leaf form inferred from KNOXI gene expression during development. Science 296: 1858-1860.

Bourque L, Lacroix C. 2011. Lobe-generating centres in the simple leaves of Myriophyllum aquaticum: evidence for KN1-like activity. Annals of Botany P1-13.

Byrne ME. 2005. Networks in leaf development. Current Opinion in Plant Biology 8: 59-66.

Chen, J., Janssen, B., Williams, A, and Sinha, N.1997. A gene fusion at a homeobox locus: alterations in leaf shape and implications for morphological evolution. The Plant Cell, 9: 12891304.

Chuck, G., Lincoln, C. and Hake, S, 1996. KNAT1 induces lobed leaves with ectopic meristem when overexpressed in Arabidopsis. The plant Cell, 8: 1277-1289.

Gallois, J-L., Woodward, C., Reddy, G. V., and Sablowski, R. 2002. Combined SHOOT MERISTEMLESS and WUSCHEL trigger ectopic organogenesis in Arabidopsis. Development, 129: $3207-3217$.

Groover, A. T., Mansfield, S. D., DiFazio, S. P., Dupper, G., Fontana, J. R., Millar, R., and Wang, Y. 2006. The Populus homeobox gene ARBORKNOX1 reveals overlapping mechanisms regulating the shoot apical meristem and the vascular cambium. Plant Mol. Biol. 61: 917-932. 
Hagemann, W. and Gleissberg, S. 1996. Organogenetic capacity of leaves: the marginal blastozones in angiosperms. P1. Syst. Evol. 199: 121-152.

Hareven, D., Gutfinger, T., Parnis, A., Eshed, Y., and Lifschitz, E. 1996. The making of a compound leaf: genetic manipulation of a compound leaf. Cell, 84: 735-744.

Harrison, J., Moller, M., Langdale, J., Cronk, Q., and Hudson, A. 2005. The role of KNOX genes in the evolution of morphological novelty in Streptocarpus. The Plant Cell, 17: 430-443.

Hay, A., Jackson, D., Ori, N., and Hake, S. 2003. Analysis of the competence to respond to KNOTTED1 activity in Arabidopsis leaves using a steroid induction system. Plant Physiology, 131: 1671-1680.

Hay, A., Craft, J., and Tsiantis, M. 2004. Plant hormones and homeoboxes: bridging the gap? BioEssays, 26: 395-404.

Hay, A., and Tsiantis, M. 2006. The genetic basis for differences in leaf form between Arabidopsis thaliana and its wild relative Cardamine hirsute. Nature Genetics, 38(8): 942-947.

Hay, A., Kaur, H., Phillips, A., Hedden, P., Hake, S., and Tsiantis, M. 2002. The gibberellin pathway mediates KNOTTED1-type homeobox function in plants with different body plans. Current Biology, 12: 1557-1565.

Hofer, J., Gourlay, C., Michael, A., and Ellis, T. H. N. 2001. Expression of a class 1 knotted1-like homeobox gene is down-regulated in pea compound leaf primordia. Plant Molecular Biology, 45: 387-398.

Huang, Z., Meilan, R., and Woeste, K. 2009. A KNAT3-like homeobox gene from Juglans nigra L., JnKNAT3-like, highly expressed during heartwood formation. Plant Cell Rep. 28(11): 17171724.

Ito, Y., and Kurata, N. 2008. Disruption of KNOX gene suppression in leaf by introducing its cDNA in rice. Plant Science, 174: 357-365. 
Janssen, B, Lund, L., and Sinha, N. 1998. Overexpression of a homeobox gene, LeT6, reveals indeterminate features in the tomato compound leaf. Plant Physiol. 117: 771-786.

Kerstetter, R., Vollbrecht, E., Lowe, B., Veit, B., Yamaguchi, J., and Hake, S. 1994. Sequence analysis and expression patterns divide the maize knottedl-like homeobox genes into two classes. The Plant Cell, 6: 1877-1887.

Kessler, S., and Sinha, N. 2004. Shaping up: the genetic control of leaf shape. Current Opinion in Plant Biology, 7:65-72.

Lincoln, C., Long, J., Yamaguchi, J., Serikawa, K., and Hake, S. 1994. A knottedl-like homeobox gene in Arabidopsis is expressed in the vegetative meristem and dramatically alters leaf morphology when overexpressed in transgenic plants. The Plant Cell, 6: 1859-1876.

Ma, H., McMullen, M. D., and Finer, J. J. 1994. Identification of a homeobox containing gene with enhanced expression during soybean (Glycine max L.) somatic embryo development. Plant Molecular Biology, 24: 465-473.

Muller, K. J., He, X., Fischer, R., and Prufer, D. 2006. Constitutive knox1 gene expression in dandelion (Taraxacum officinale, Web.) changes leaf morphology from simple to compound. Planta, 224: 1023-1027.

Orchard, A. E. 1979. Myriophyllum (Haloragaceae) in Australia. I. New Zealand: A revision of the genus and a synopsis of the family. Brunonia, 2: 247-287.

Perrot, E. 1900. Sur les organs appendiculaires des feuilles de certains Myriophyllum. Journal de Botanique, 14: 198-202.

Rosin, F. M., Jennifer, K. Hart, J. K., Horner, H. T., Davies, P. J., and Hannapel, D. J. 2003. Overexpression of a knotted-Like homeobox gene of potato alters vegetative development by decreasing gibberellin accumulation. Plant Physiology, 132: 106-117. 
Rothwell, G. W., S. E. Wyatt, and A. M. F. Tomescu. 2014. Plant evolution at the interface of paleontology and developmental biology: an organism-centered paradigm. American Journal of Botany. 101(6): 899-913.

Sano, R., Juarez, C. M., Hass, B., Sakakibara, K., Ito, M., Banks, J. A., and Hasebea, M. 2005. KNOX homeobox genes potentially have similar function in both diploid unicellular and multicellular meristems, but not in haploid meristems. Evolution and Development, 7(1): 69-78.

Sentoku, N., Tamaoki, M., Nishimura, A., and Matsuoka, M. 1998. The homeobox gene NTH23 of tobacco is expressed in the basal region of leaf primordia. Biochimica et Biophysica Acta, 1399: 203-208.

Serikawa, K. A., Martinez-Laborda, A., and Zambryski, P. 1996. Three knotted-like homeobox genes in Arabidopsis. Plant Molecular Biology, 32: 673-683.

Serikawa, K. A., Martinez-Laborda, A., Kim, H., and Zambryski, P. C. 1997. Localization of expression of KNAT3, a class 2 knotted1-like gene. The Plant Journal, 11(4): 853-861.

Serikawa, K. A., and Mandoli, D. F. 1999. Aaknox1, a kn1-like homeobox gene in Acetabularia acetabulum, undergoes developmentally regulated subcellular localization. Plant Molecular Biology, 41: 785-793.

Shafiullah, M. and Lacroix C.R. 2013. Comparative leaf development of aerial and aquatic growth forms of Myriophyllum aquaticum. Botany, 91:421-430.

Smith, L. G., Greene, B., Veit, B., and Hake, S. 1992. A dominant mutation in the maize homeobox gene, Knotted-1, causes its ectopic expression in leaf cells with altered fates. Development, 116: 21-30.

Steingraeber, D. A. and Fisher, J. B. 1986. Indeterminate growth of leaves in Guarea (Meliaceae): A twig analogue. Amer. J. Bot. 73(6): 852-862. 
Sundas-Larsson, A., Svenson, M., Liao, H., and Engstrom, P. 1998. A homeobox gene with potential developmental control function in the meristem of the conifer Picea abies. Proc. Natl. Acad. Sci. USA, 95: 15118-15122.

Tioni, M. F., Gonzalez, D. H., and Chan, R. L. 2003. Knotted1-like genes are strongly expressed in differentiated cell types in sunflower. Journal of Experimental Botany, 54(383): 681-690.

Vollbrecht, E., Veit, B., Sinha, N., and Hake, S. 1991. The developmental gene knotted-1 is a member of a maize homeobox gene family. Nature, 350: 241-243

Watillon, B., Kettmann, R., Boxus, P., and Burny, A. 1997. Knotted1-like homeobox genes are expressed during apple tree (Malus domestica [L.] Borkh) growth and development. Plant Molecular Biology, 33: 757-763. 


\section{Figure Legends}

Fig. 1. $A, C, D \& E$ are aquatic and $B \& F$ are aerial leaf forms of $M$. aquaticum. LP \& LD [typical lobes in the proximal $(P)$ and distal $(D)$ part of the leaf], AA (hydathode appendage in axil of lobes), AL (hydathode appendage on lobe), AT (hydathode appendage on tip of lobe) and AN (hydathode appendage in nodal area). Scale bar $=2.84 \mathrm{~mm}(\mathrm{~A} \& \mathrm{~B}), 0.62 \mathrm{~mm}(\mathrm{C}, \mathrm{D} \&$ E) \& $0.5 \mathrm{~mm}(\mathrm{~F})$.

Fig. 2. A, B, \& $C$ showing hybridization signal with anti-sense RNA probe in longitudinal sections of shoot tips of aquatic leaf forms of $M$. aquaticum. Signal shows up as a reddish stain. D is the negative control (no staining). M (SAM), MA (apical meristem of axillary bud), P1 to P12 indicate the relative age of leaf primordia from youngest to oldest, LP (lobes in the proximal part of the leaf), LD (lobes in the distal part of the leaf), CR (center of midrib), OR (outer portion of the midrib), IN (internode), SA (sub-apical), VS (vascular strand), leaf vasculature (LV), PH (pith). Scale bar $=250 \mu \mathrm{m}$.

Fig. 3. A, B, \& $C$ showing hybridization signal with anti-sense RNA probe in the cross sections (from upper to lower portions) of the shoot. Signal shows up as a reddish stain. D is the negative control (no staining). P5-10 indicate the relative age of leaf primordia from youngest to oldest. VC (vascular cylinder), * (adaxial portion of leaf ), OI (outer portion of internode), $\mathrm{PH}$ (pith), CR (center of the midrib), OR (outer portion of midrib), L (lobe), SL (site of attachment of lobe to the leaf), $\mathrm{OL}$ (older lobe), $\mathrm{VL}$ (vascular tissue supply to the leaf), $\mathrm{BL}$ (base of the leaf), LP (lobe in the proximal part of the leaf) and AN (hydathode between the base of two leaves). Scale bar $=250 \mu \mathrm{m}$. 


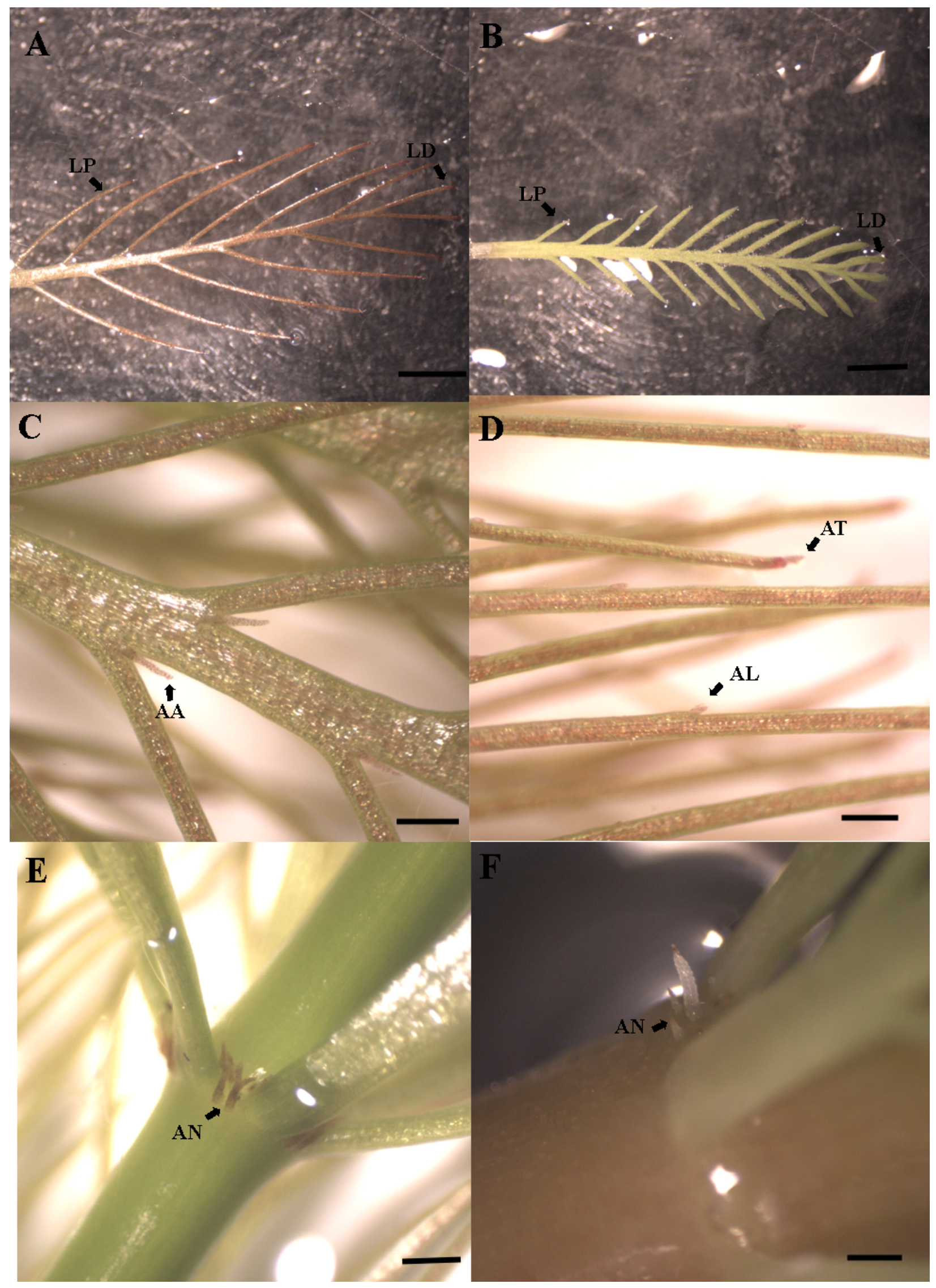




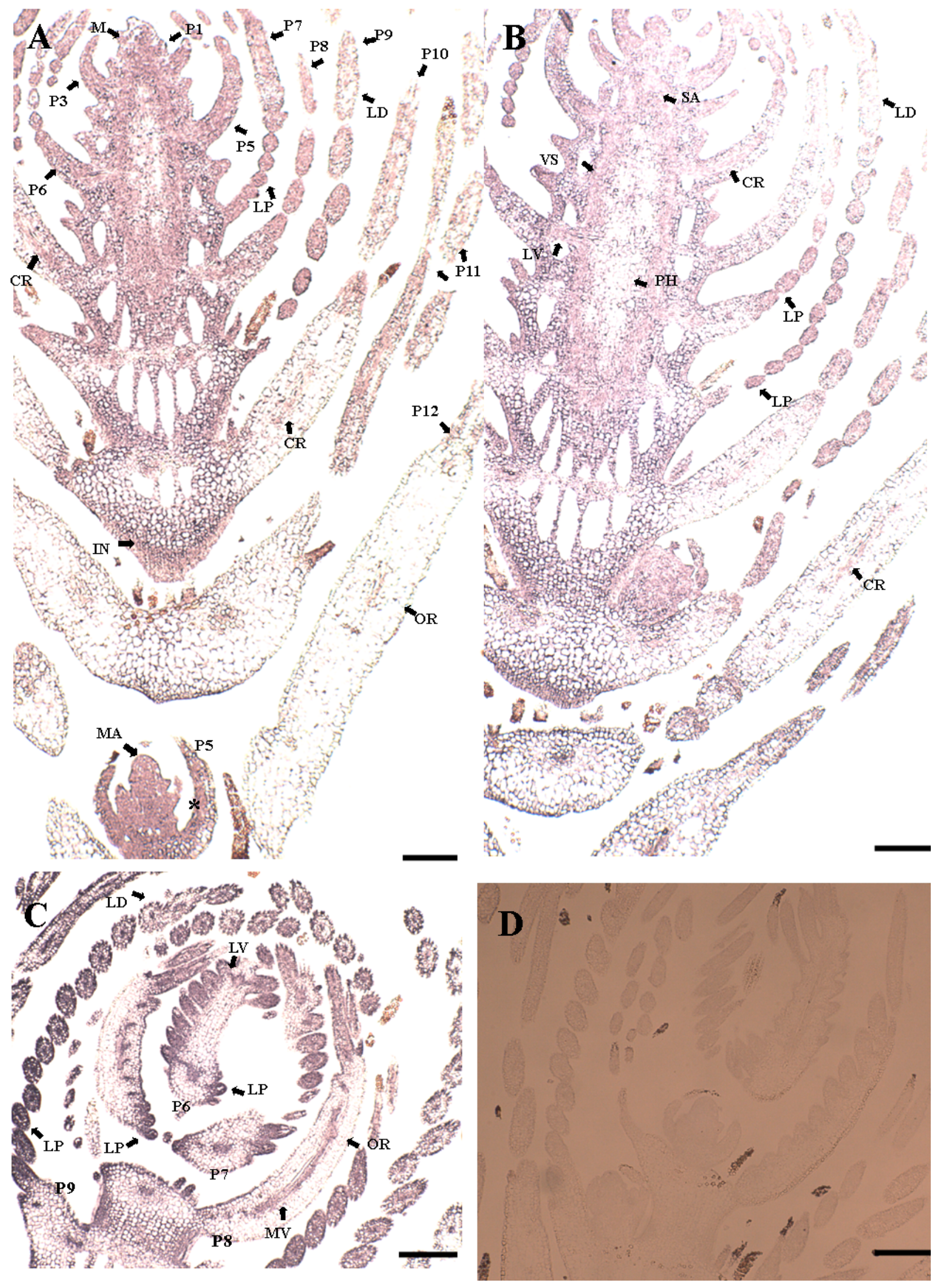


A.
H

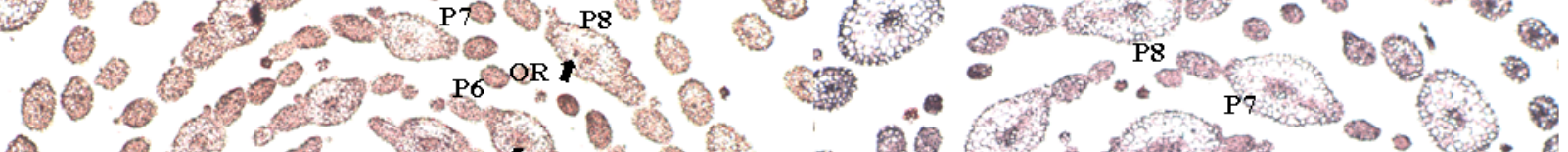
10.

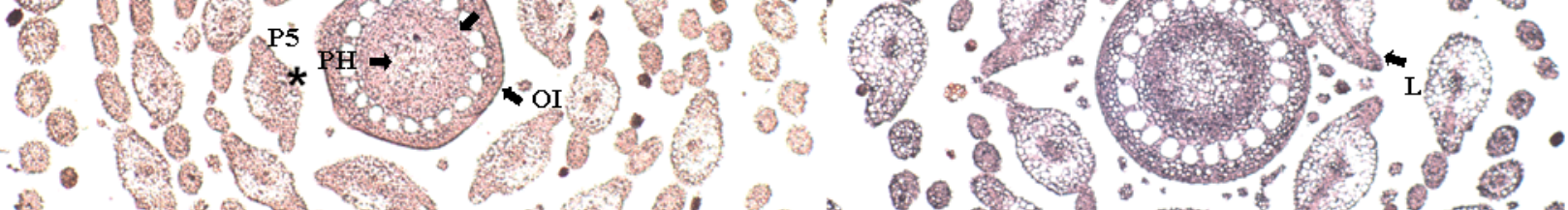

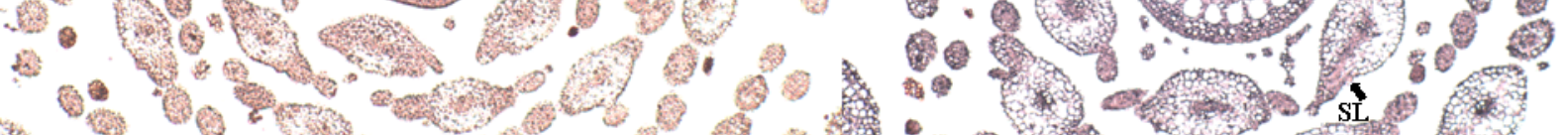

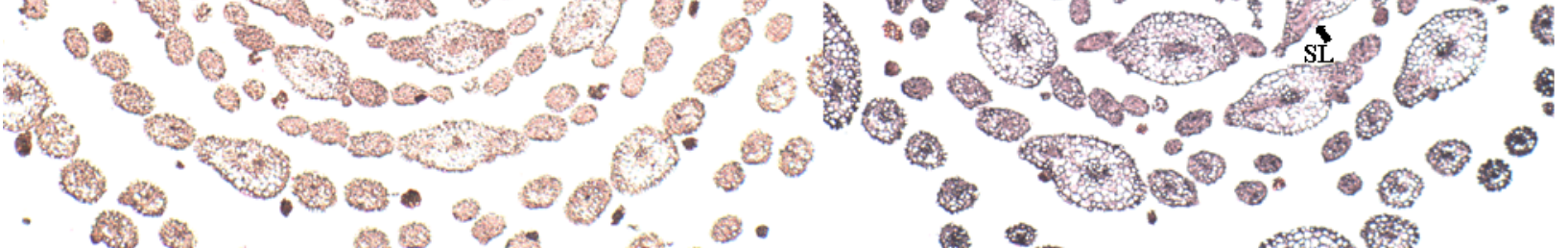
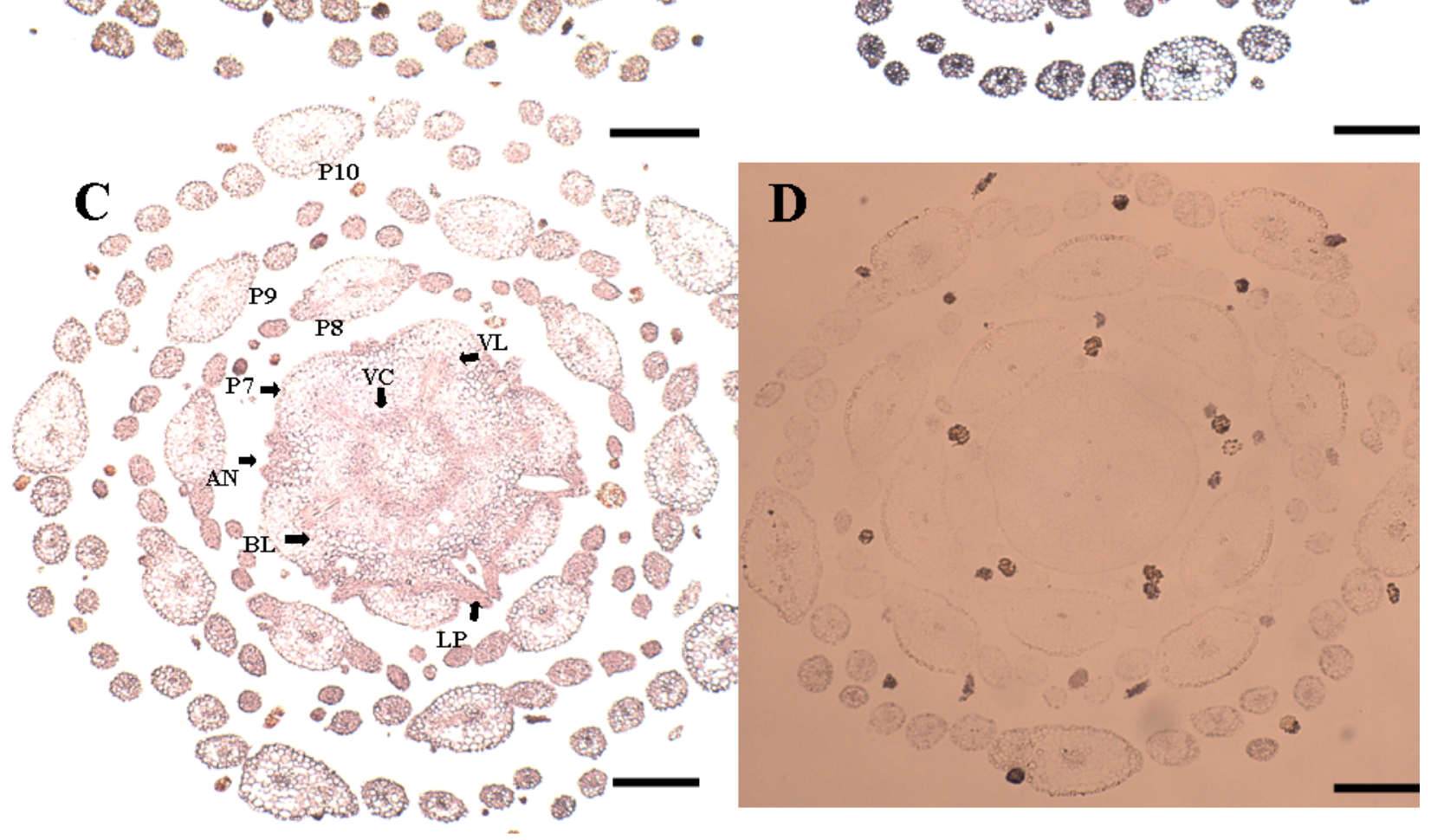